Pacific Journal of Mathematics

ABEL SUMMABILITY OF CONJUGATE INTEGRALS 


\title{
ABEL SUMMABILITY OF CONJUGATE INTEGRALS
}

\section{STANTON PHILIPP}

\begin{abstract}
It is proved here that the conjugate Fourier-Stieltjes integral of a finite-valued Borel measure $\mu$ on Euclidean $k$ space, $k \geqq 1$, taken with respect to a Calderon-Zygmund kernel in Lip $\alpha, 0<\alpha<1$, is almost everywhere (with respect to Lebesgue measure) Abel summable to the conjugate function of $\mu$ taken with respect to the above mentioned kernel. This has been already established for $k \leqq 3$ and for $k$ even.
\end{abstract}

We make the following assumptions: $k$ is a positive integer; $0<$ $\alpha<1 ; \Omega \in \operatorname{Lip} \alpha(S)$, where $S$ denotes the $(k-1)$-sphere in $k$-dimensional Euclidean 'space $E_{k} ; \int_{S} \Omega(y) d S(y)=0$, where $d S$ refers to the natural measure on $S$; and $\mu$ is a real Borel measure on $E_{k}$ as defined in [3].

Let $K(x)=\Omega(x /|x|)|x|^{-k}$ for each nonzero $x$ in $E_{k}$ (we use $|x|$ for the usual norm and $x \cdot y$ for the usual dot product and $d x$ for Lebesgue measure, all in $\left.E_{k}\right)$. For $y$ in $E_{k}$, set $\hat{\mu}(y)=(2 \pi)^{-k} \int_{E_{k}} e^{-i x \cdot y} d \mu(x)$ and

$$
\hat{K}(y)=(2 \pi)^{-k} \lim _{\substack{\varepsilon \rightarrow 0 \\ R \rightarrow \infty}} \int_{\varepsilon \leqq|x| \leqq R} e^{-i x \cdot y} K(x) d x .
$$

It is known [5, p. 69] that $\hat{K}$ is bounded on $E_{k}$. We define, for $t>0$ and $x$ in $E_{k}$,

$$
I_{t}(x)=(2 \pi)^{k} \int_{E_{k}} e^{-t|y|} \hat{k}(y) \hat{\mu}(y) e^{i x \cdot y} d y .
$$

We shall prove the

THEOREM.

$$
\lim _{t \rightarrow 0}\left[I_{t}(x)-\int_{|y-x|>t} K(x-y) d \mu(y)\right]=0
$$

except on a set of Lebesgue measure zero in $E_{k}$.

If $k=1$, the theorem is classical (see [8, p. 103] for the essence of the matter). The case $k=2$ and $1 / 2<\alpha<1$ was treated in [4]. The cases in which $0<\alpha<1$ and $k=3$ or $k$ is even were handled in [2]. Further references and motivation for the theorem are given in [2] and [4]. The proof given in the present paper covers all cases with $0<\alpha<1$ and $k \geqq 3$; modifications could be made in the proof to cover the cases $k=2,0<\alpha<1$ and $k=1$, but this seems pointless. 
Proof of the theorem. Assume $k \geqq 3$. Define, for $t>0$ and $n=$ $1,2, \cdots$,

$$
H_{n}^{k}(t)=\frac{\Gamma\left(\frac{n}{2}\right)}{2^{k / 2} \Gamma\left(\frac{n+k}{2}\right)} \int_{0}^{\infty} e^{-t s} s^{k / 2} J_{n-1+k / 2}(s) d s,
$$

where $J_{n-1+k / 2}(s)$ denotes a standard Bessel function of first kind. We assume throughout that $t>0$. It follows from (1) and [6, p. 385] and $[7$, p. 282] that for $n=1,2, \cdots$,

$$
\begin{aligned}
0 & \leqq H_{n}^{k}(t) \\
& =\frac{\Gamma\left(\frac{n}{2}\right) \Gamma\left(\frac{n+k+1}{2}\right) \pi^{-1 / 2}}{\Gamma\left(n+\frac{k}{2}\right)\left(t^{2}+1\right)^{(n+k) / 2}} F\left(\frac{n+k}{2}, \frac{n-1}{2} ; n+\frac{k}{2} ; \frac{1}{1+t^{2}}\right) \\
& \leqq\left(\frac{1}{1+t^{2}}\right)^{(k+n) / 2} .
\end{aligned}
$$

Here and throughout $F(a, b ; c ; x)$ refers to Gauss' hypergeometric series. Let the series of spherical harmonics associated with $\Omega(\xi)$ be $\sum_{n=1}^{\infty} Y_{n}(\xi)$. Let $\omega$ denote the $(k-1)$-dimensional volume of $S$ and let $\xi$ be a point of $S$. We shall use the symbol $A$ generically to denote any positive constant which depends only on $\Omega$ and $k$. Let $\lambda=(k-2) / 2$. The Gegenbauer polynomials $P_{n}^{\lambda}(\cos \theta)$ are defined in [5]. By (2) and the boundedness of $\Omega$ and the fact [1, p. 245] that

$$
P_{n}^{\lambda}(\cos \theta) \mid \leqq P_{n}^{\lambda}(1) \leqq A n^{2 \lambda-1}
$$

for $n=0,1,2, \cdots$ and $0 \leqq \theta \leqq \pi$, we may write

$$
\begin{aligned}
\sum_{n=1}^{\infty} H_{n}^{k}(t) Y_{n}(\xi) & =\sum_{n=1}^{\infty} H_{n}^{k}(t) \frac{n+\lambda}{\lambda \omega} \int_{S} \Omega(y) P_{n}^{\lambda}(\xi \cdot y) d S(y) \\
& =\frac{1}{\omega} \int_{S} \Omega(y)\left[\sum_{n=1}^{\infty} \frac{n+\lambda}{\lambda} H_{n}^{k}(t) P_{n}^{\lambda}(\xi \cdot y)\right] d S(y) .
\end{aligned}
$$

By the concluding argument given in [2], we see that in order to prove the theorem it suffices to prove that

$$
\left|\sum_{n=1}^{\infty} H_{n}^{k}(t) Y_{n}(\xi)-\Omega(\xi)\right| \leqq A t^{\alpha} .
$$

So we define a kernel $K_{t}(\theta)$ by

$$
K_{t}(\theta)=1+\sum_{n=1}^{\infty} \frac{n+\lambda}{\lambda} H_{n}^{k}(t) P_{n}^{\lambda}(\cos \theta)
$$


for $0 \leqq \theta \leqq \pi$. Now

$$
\frac{1}{\omega} \int_{S} K_{t}(\xi \cdot y) d S(y)=1,
$$

as may be seen from (4). It follows from (4), (6), and (7) that

$$
\sum_{n=1}^{\infty} H_{n}^{k}(t) Y_{n}(\xi)-\Omega(\xi)=\frac{1}{\omega} \int_{S}[\Omega(y)-\Omega(\xi)] K_{t}(\xi \cdot y) d S(y) .
$$

Notice that if we can establish that

$$
\left|K_{t}(\theta)\right| \leqq \frac{A t}{\left(t^{2}+\sin ^{2} \frac{\theta}{2}\right)^{k / 2}}
$$

for $0 \leqq \theta \leqq \pi$, then it will follow from (8), (9), and the Lipschitz condition on $\Omega$ that

$$
\begin{aligned}
& \left|\sum_{n=1}^{\infty} H_{n}^{k}(t) Y^{u}(\xi)-\Omega(\xi)\right| \leqq A \int_{S}\left|K_{t}(\xi \cdot y)\right| \cdot|y-\xi|_{\alpha} d S(y) \\
& \quad \leqq A t \int_{0}^{\pi} \frac{(1-\cos \theta)^{\alpha / 2} \sin ^{k-2} \theta}{\left(t^{2}+\sin ^{2} \frac{\theta}{2}\right)^{k / 2}} d \theta \leqq A \int_{0}^{\pi} \frac{t \theta^{k-2+\alpha}}{\left({ }^{2} t+\theta^{2}\right)^{k / 2}} d \theta \leqq A t^{\alpha} .
\end{aligned}
$$

That is, once we prove (9), then (5) follows and we are done.

Now define

$$
P_{\nu}(s, t)=\int_{0}^{\infty} e^{-t y} y s^{1 / 2} J_{\nu}(s y) J_{\nu}(y) d y
$$

for $\nu>-(1 / 2)$ and $s>0$. The relations

$$
J_{\nu}(x)=0\left(x^{-1 / 2}\right) \text { as } x \rightarrow \infty, J_{\nu}(x)=0\left(x^{\nu}\right) \text { as } \quad x \rightarrow 0+\text {, }
$$

which are valid for each $\nu>-(1 / 2)$ and are proved in [6], will be useful to us. Using (10), (11), Fubini's theorem, the change of variable $s y=r$ and $[6, \mathrm{p} .391]$, we obtain that

$$
\begin{aligned}
& \int_{0}^{\infty} s^{-\lambda-3 / 2} P_{n+\lambda}(s, t) d s \\
& \quad=\int_{0}^{\infty} e^{-t y} y^{\lambda+1} J_{n+\lambda}(y) d y \int_{0}^{\infty} r^{-\lambda-1} J_{n+\lambda}(r) d r=H_{n}^{k}(t)
\end{aligned}
$$

for $n \geqq 1$. It follows from (6) and (12) that

$$
K_{t}(\theta)=1+\sum_{n=1}^{\infty} \frac{n+\lambda}{\lambda} P_{n}^{\lambda}(\cos \theta) \int_{0}^{\infty} s^{-\lambda-3 / 2} P_{n+\lambda}(s, t) d s
$$

for $0 \leqq \theta \leqq \pi$. By Gegenbauer's addition theorem [6, p. 363] we may write 


$$
\begin{aligned}
& \frac{J_{\lambda}\left(y \sqrt{\left.s^{2}-2 s \cos \theta+1\right)} s^{\lambda+1 / 2} y^{\lambda+1} e^{-t y}\right.}{\left(s^{2}-2 s \cos \theta+1\right)^{\lambda / 2} 2^{\lambda} \Gamma(\lambda+1)} \\
& \quad=\sum_{n=0}^{\infty} \frac{n+\lambda}{\lambda} y s^{1 / 2} J_{n+\lambda}(y) J_{n+\lambda}(s y) P_{n}^{\lambda}(\cos \theta) e^{-t y}
\end{aligned}
$$

for $y>0, s>0,0 \leqq \theta \leqq \pi$. Because of (3) and the inequality [6, p. 49]

$$
\left|J_{n+\lambda}(x)\right| \leqq \frac{A x^{n+\lambda}}{\Gamma(n+\lambda)},
$$

valid for $x>0$ and $n \geqq 0$, we may integrate the right member of (14) term by term with respect to $y$ over $(0, \infty)$. So, by integrating both sides of (14) with respect to $y$ over $(0, \infty)$ and then using (10) in the right member and $[6$, p. 391] in the left member, we obtain that

$$
\begin{aligned}
\sum_{n=1}^{\infty} \frac{n+\lambda}{\lambda} P_{n+\lambda}(s, t) P_{n}^{\lambda}(\cos \theta) & \\
= & \frac{\Gamma\left(\lambda+\frac{3}{3}\right) t(z-\cos \theta)^{-\lambda-3 / 2}}{2^{\lambda+1 / 2} \Gamma(\lambda+1) \pi^{1 / 2} s}-P_{\lambda}(s, t)
\end{aligned}
$$

for $0 \leqq \theta \leqq \pi, s>0$, where

$$
z=\frac{s^{2}+t^{2}+1}{2 s}
$$

for $s>0$. We shall adhere to the notation (16). It follows from [6, p. 389] and [7, pp. 317 and 281] that

$$
\begin{aligned}
P_{\nu}(s, t) & \\
= & \frac{\Gamma\left(\nu+\frac{3}{2}\right) t s^{-1}}{2^{\nu+1 / 2} \pi^{1 / 2} \Gamma(\nu+1)} z^{-\nu-3 / 2} F\left(\frac{\nu+\frac{1}{2}}{2}, \frac{\nu+\frac{3}{2}}{2}: \nu+1 ; z^{-2}\right) \\
& +\frac{\Gamma\left(\nu+\frac{5}{2}\right) t s^{-1}}{2^{\nu+3 / 2} \pi^{1 / 2} \Gamma(\nu+2)} z^{-\nu-7 / 2} F\left(\frac{\nu+\frac{5}{2}}{2}, \frac{\nu+\frac{7}{2}}{2}: \nu+2 ; z^{-2}\right)
\end{aligned}
$$

for $\nu>1 / 2$ and $s>0$. Proceeding formally, we multiply both sides of (15) by $s^{-\lambda-3 / 2}$ and integrate with respect to $s$ over $(0, \infty)$ term by term in the left member; using (13), the result is that

$$
\begin{aligned}
& K_{t}(\theta) \\
& \quad=1+\int_{0}^{\infty} s^{-\lambda-3 / 2}\left[\frac{\Gamma\left(\lambda+\frac{3}{2}\right) t(z-\cos \theta)^{-\lambda-3 / 2}}{2^{\lambda+1 / 2} \Gamma(\lambda+1) \pi^{1 / 2} s}-P_{\lambda}(s, t)\right] d s
\end{aligned}
$$


for $0 \leqq \theta \leqq \pi$. To justify this formal procedure, we observe that, by (17), $P_{n+\lambda}(s, t) \geqq 0$ for $n \geqq 1, s>0$; therefore, by (3), (15) and Fubini's theorem, we can be sure that (18) holds if the integral in the right member of (18) is a finite Lebesgue integral when $\theta=0$. But it follows from (17) that for fixed $t$ and $\theta=0$, the integrand in the right member of (18) is $O(1)$ as $s \rightarrow 0$; and by (10) and (11), this same integrand is $O\left(s^{-\lambda-3 / 2}\right)$ as $s \rightarrow \infty$. Therefore (18) holds.

We proceed to estimate the right member of (18) by using the expression for $P_{\lambda}(s, t)$ given by (17). Observe that if $s>0$ and $|s-1| \geqq$ $1 / 2$, then $z \geqq 13 / 12$; and recall that the radius of convergence of the hypergeometric series is at least one. Therefore, using [7, p. 299, Ex. 18], we may write

$$
F\left(\frac{\lambda+\frac{1}{2}}{2}, \frac{\lambda+\frac{3}{2}}{2} ; \lambda+1 ; z^{-2}\right)=1+\varphi(z),
$$

where

$$
|\varphi(z)| \leqq A z^{-2} \quad \text { for } \quad|s-1| \geqq \frac{1}{2}, \quad s>0,
$$

and

$$
|\varphi(z)| \leqq A \log \left(1-z^{-2}\right)^{-1} \quad \text { for } \quad|s-1|<\frac{1}{2} .
$$

It follows from (20) and (21) that

$$
\int_{0}^{\infty} s^{-\lambda-3 / 2} t z^{-\lambda-3 / 2} s^{-1} \varphi(z) d s=0(t) \quad \text { as } \quad t \rightarrow 0 .
$$

We conclude from (17), (18), (19), and (22) that, as $t \rightarrow 0$,

$$
K_{t}(\theta)=O(t)+B(t, \theta)+\psi(t)
$$

for $0 \leqq \theta \leqq \pi$, where we have set

$$
B(t, \theta)=\frac{\Gamma\left(\lambda+\frac{3}{2}\right) t}{2^{\lambda+1 / 2} \pi^{1 / 2} \Gamma(\lambda+1)} \int_{0}^{\infty} s^{-\lambda-5 / 2}\left[(z-\cos \theta)^{-\lambda-3 / 2}-z^{-\lambda-3 / 2}\right] d s
$$

for $0 \leqq \theta \leqq \pi$ and

$$
\begin{aligned}
\psi(t)=1 & -\frac{\Gamma\left(\lambda+\frac{5}{2}\right) t}{2^{\lambda+3 / 2} \pi^{1 / 2} \Gamma(\lambda+2)} \\
& \times \int_{0}^{\infty} s^{-\lambda-5 / 2} z^{-\lambda-7 / 2} F\left(\frac{\lambda+\frac{5}{2}}{2}, \frac{\lambda+\frac{7}{2}}{2}, \lambda+2 ; z^{-2}\right) d s .
\end{aligned}
$$


By the mean value theorem we may write, for $0 \leqq \theta \leqq \pi$,

$$
\begin{aligned}
B(t, \theta) & =A t \int_{0}^{\infty} s^{-\lambda-s / 2}\left(\frac{1}{z-\cos \theta}-\frac{1}{z}\right) w^{\lambda+1 / 2} d s \\
& =A t \int_{0}^{\infty} \frac{s^{-\lambda-5 / 2}(\cos \theta) w^{\lambda+1 / 2}}{z(z-\cos \theta)} d s,
\end{aligned}
$$

where $w$ lies between $z^{-1}$ and $(z-\cos \theta)^{-1}$. If $\pi / 2 \leqq \theta \leqq \pi$, we obtain from (26) that

$$
|B(t, \theta)| \leqq A t \int_{0}^{\infty} \frac{s^{-\lambda-5 / 2}}{z^{2}}\left(\frac{1}{z}\right)^{\lambda+1 / 2} d s \leqq A t .
$$

If $0 \leqq \theta \leqq \pi / 2$, we obtain from (26) that

$$
\begin{aligned}
|B(t, \theta)| & \leqq A t \int_{0}^{\infty} \frac{s^{-\lambda-s / 2}}{z(z-\cos \theta)^{\lambda+3 / 1}} d s \\
& \leqq A t \int_{0}^{\infty} \frac{d s}{\left[(s-\cos \theta)^{2}+t^{2}+\sin ^{2} \theta\right]^{\lambda+3 / 2}} \\
& \leqq A t \int_{-\infty}^{\infty} \frac{d s}{\left[(s-\cos \theta)^{2}+t^{2}+\sin ^{2} \theta\right]^{\lambda+3 / 2}} \\
& =\frac{A t}{\left(t^{2}+\sin ^{2} \theta\right)^{k / 2}} .
\end{aligned}
$$

It follows from these estimates that

$$
|B(t, \theta)| \leqq \frac{A t}{\left(t^{2}+\sin ^{2} \frac{\theta}{2}\right)^{k / 2}}
$$

for $0 \leqq \theta \leqq \pi$. Now we wish to estimate $\psi(t)$. It is shown in [7, pp. 286 and 282] that

(28)

$$
\begin{aligned}
& F\left(\frac{\lambda+\frac{5}{2}}{2}, \frac{\lambda+\frac{7}{2}}{2} ; \lambda+2 ; z^{-2}\right) \\
& \quad=\left(1-z^{-2}\right)^{-1} F\left(\frac{\lambda+\frac{1}{2}}{2}, \frac{\lambda+\frac{3}{2}}{2} ; \lambda+2 ; z^{-2}\right)
\end{aligned}
$$

and

$$
\lim _{x \rightarrow-0} F\left(\frac{\lambda+\frac{1}{2}}{2}, \frac{\lambda+\frac{3}{2}}{2} ; \lambda+2 ; x\right)=L,
$$

where 


$$
L=\frac{\Gamma(\lambda+2)}{\Gamma\left(\frac{\lambda+5 / 2}{2}\right) \Gamma\left(\frac{\lambda+1 / 2}{2}\right)} .
$$

So, by (25) and (28), we have that

$$
\begin{aligned}
\psi(t)= & {\left[1-\frac{L \Gamma\left(\lambda+\frac{5}{2}\right) t}{2^{\lambda+3 / 2} \pi^{1 / 2} \Gamma(\lambda+2)} \int_{0}^{\infty} s^{-\lambda-5 / 2} z^{-\lambda-7 / 2}\left(1-z^{-2}\right)^{-1} d s\right] } \\
& +\frac{\Gamma\left(\lambda+\frac{5}{2}\right) t}{2^{\lambda+3 / 2} \pi^{1 / 2} \Gamma(\lambda+2)} \int_{0}^{\infty} s^{-\lambda-5 / 2} z^{-\lambda-7 / 2} \\
& \times\left[\frac{L-F\left(\frac{\lambda+1 / 2}{2}, \frac{\lambda+3 / 2}{2} ; \lambda+2 ; z^{-2}\right.}{1-z^{-2}}\right] d s
\end{aligned}
$$

Using (29), [7, p. 281], the mean value theorem, and then estimates of the type (20) and (21), all in the second term of the right member of (30), we obtain after simplifying the gamma functions which occur in the first term of the right member of (30) that

$$
\psi(t)=\left[1-\frac{t}{\pi} \int_{0}^{\infty} s^{-\lambda-5 / 2} z^{-\lambda-7 / 2}\left(1-z^{-2}\right)^{-1} d s\right]+O(t)
$$

as $t \rightarrow 0$. It follows from (31) and (16) and the change of variable $s=1+x t$ that

$$
\begin{aligned}
\psi(t)= & O(t)+1-2^{\lambda+3 / 2} \frac{t}{\pi} \int_{0}^{\infty}\left(s^{2}+t^{2}+1\right)^{-\lambda-3 / 2} \\
& \times\left[\frac{1}{(s-1)^{2}+t^{2}}-\frac{1}{(s+1)^{2}+t^{2}}\right] d s \\
= & O(t)+1-2^{\lambda+3 / 2} \frac{t}{\pi} \int_{0}^{\infty}\left(s^{2}+t^{2}+1\right)^{-\lambda-3 / 2}\left[(s-1)^{2}+t^{2}\right]^{-1} d s \\
= & O(t)+1-2^{\lambda+3 / 2} \frac{t}{\pi} \int_{1 / 2}^{3 / 2}\left(s^{2}+t^{2}+1\right)^{-\lambda-3 / 2}\left[(s-1)^{2}+t^{2}\right]^{-1} d s \\
= & O(t)+1-\frac{1}{\pi} \int_{-1 / 2 t}^{1 / 2 t}\left(1+\frac{t^{2}+x^{2} t^{2}+2 x t}{2}\right)^{-\lambda-3 / 2} \frac{d x}{1+x^{2}}
\end{aligned}
$$

as $t \rightarrow 0$. So, assuming as we may that $0<t<1 / 4$ and using the binomial theorem, we obtain from (32) that

$$
\begin{aligned}
\psi(t)= & O(t)+\left[1-\frac{1}{\pi} \int_{-1 / 2 t}^{1 / 2 t} \frac{d x}{1+x^{2}}\right] \\
& +\frac{(\lambda+3 / 2)}{2 \pi} \int_{-1 / 2 t}^{1 / 2 t} \frac{t^{2}+x^{2} t^{2}+2 x t}{1+x^{2}} d x
\end{aligned}
$$




$$
\begin{gathered}
+\frac{1}{\pi} \int_{-1 / 2 t}^{1 / 2 t} \frac{O\left(\left(t^{2}+x^{2} t^{2}+2 x t\right)^{2}\right)}{1+x^{2}} d x \\
=O(t)+O(t)+O(t)+O(t)=O(t)
\end{gathered}
$$

as $t \rightarrow 0$. Finally, (9) follows from (23), (27), and (33).

\section{REFERENCES}

1. A. Erdélyi, W. Magnus, F. Oberhettinger, and F. G. Tricomi, Higher Transcendental Functions, 2, New York, 1953.

2. S. Philipp, V. L. Shapiro, and W. H. Sills, On the Conjugate Multiple Fourier-Stieltjes Integral, to appear.

3. W. Rudin, Real and Complex Analysis, McGraw-Hill, 1966.

4. V. L. Shapiro, The conjugate Fourier-Stieltjes integral in the plane, Bull. Amer. Math. Soc., 65 (1959), 12-15.

5. - Topics in Fourier and geometric analysis, Amer. Math. Soc. Memoir, Number 39, 1961.

6. G. N. Watson, A Treatise on the Theory of Bessel Functions, Cambridge, 1922.

7. E. T. Whittaker and G. N. Watson, A Course of Modern Analysis, Cambridge, 1927.

8. A. Zygmud, Trigonometric Series, 1, Cambridge, 1959.

9. A. P. Calderón and A. Zygmund, On the existence of certain singular integrals, Acta Math., 88 (1952), 25-139.

Received March 3, 1971.

University of California, Santa Cruz 


\section{PACIFIC JOURNAL OF MATHEMATICS}

\section{EDITORS}

\section{H. SAMELSON}

Stanford University

Stanford, California 94305

C. R. Новву

University of Washington Seattle, Washington 98105

\section{J. DuGundJI}

Department of Mathematics University of Southern California Los Angeles, California 90007

RICHARD ARENS

University of California Los Angeles, California 90024

\section{ASSOCIATE EDITORS}
E. F. BECKENBACH
B. H. NeumanN
F. WOLF
K. YoSHIDA

\section{SUPPORTING INSTITUTIONS}

\author{
UNIVERSITY OF BRITISH COLUMBIA \\ CALIFORNIA INSTITUTE OF TECHNOLOGY \\ UNIVERSITY OF CALIFORNIA \\ MONTANA STATE UNIVERSITY \\ UNIVERSITY OF NEVADA \\ NEW MEXICO STATE UNIVERSITY \\ OREGON STATE UNIVERSITY \\ UNIVERSITY OF OREGON \\ OSAKA UNIVERSITY
}

\author{
UNIVERSITY OF SOUTHERN CALIFORNIA \\ STANFORD UNIVERSITY \\ UNIVERSITY OF TOKYO \\ UNIVERSITY OF UTAH \\ WASHINGTON STATE UNIVERSITY \\ UNIVERSITY OF WASHINGTON \\ $*{ }^{*}$
AMERICAN MATHEMATICAL SOCIETY
NAVAL WEAPONS CENTER
}

The Supporting Institutions listed above contribute to the cost of publication of this Journal, but they are not owners or publishers and have no responsibility for its content or policies.

Mathematical papers intended for publication in the Pacific Journal of Mathematics should be in typed form or offset-reproduced, (not dittoed), double spaced with large margins. Underline Greek letters in red, German in green, and script in blue. The first paragraph or two must be capable of being used separately as a synopsis of the entire paper. The editorial "we" must not be used in the synopsis, and items of the bibliography should not be cited there unless absolutely necessary, in which case they must be identified by author and Journal, rather than by item number. Manuscripts, in duplicate if possible, may be sent to any one of the four editors. Please classify according to the scheme of Math. Rev. Index to Vol, 39. All other communications to the editors should be addressed to the managing editor, Richard Arens, University of California, Los Angeles, California, 90024.

50 reprints are provided free for each article; additional copies may be obtained at cost in multiples of 50 .

The Pacific Journal of Mathematics is issued monthly as of January 1966. Regular subscription rate: $\$ 48.00$ a year (6 Vols., 12 issues). Special rate: $\$ 24.00$ a year to individual members of supporting institutions.

Subscriptions, orders for back numbers, and changes of address should be sent to Pacific Journal of Mathematics, 103 Highland Boulevard, Berkeley, California, 94708.

PUBLISHED BY PACIFIC JOURNAL OF MATHEMATICS, A NON-PROFIT CORPORATION

Printed at Kokusai Bunken Insatsusha (International Academic Printing Co., Ltd.), 270, 3-chome Totsuka-cho, Shinjuku-ku, Tokyo 160, Japan. 


\section{Pacific Journal of Mathematics}

\section{Vol. 44, No. $2 \quad$ June, 1973}

Tsuyoshi Andô, Closed range theorems for convex sets and linear liftings . . . . . . 393

Richard David Bourgin, Conically bounded sets in Banach spaces . . . . . . . . . 411

Robert Jay Buck, Hausdorff dimensions for compact sets in $R^{n} \ldots \ldots \ldots \ldots \ldots \ldots . \ldots 421$

Henry Cheng, A constructive Riemann mapping theorem ................ 435

David Fleming Dawson, Summability of subsequences and stretchings of

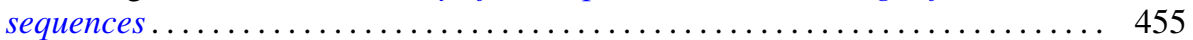

William Thomas Eaton, A two sided approximation theorem for 2-spheres ....... 461

Jay Paul Fillmore and John Herman Scheuneman, Fundamental groups of compact complete locally affine complex surfaces ....................... 487

Avner Friedman, Bounded entire solutions of elliptic equations . . . . . . . . . . . 497

Ronald Francis Gariepy, Multiplicity and the area of an $(n-1)$ continuous

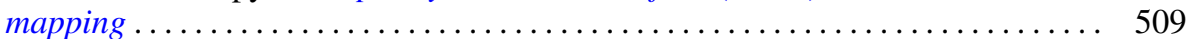

Andrew M. W. Glass, Archimedean extensions of directed interpolation groups . . . . 515

Morisuke Hasumi, Extreme points and unicity of extremum problems in $H^{1}$ on

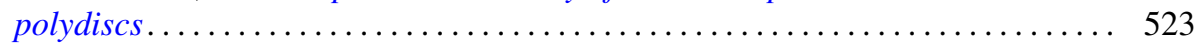

Trevor Ongley Hawkes, On the Fitting length of a soluble linear group . . . . . . 537

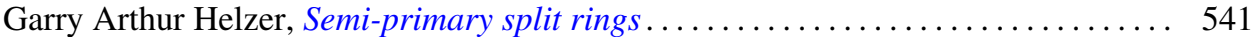

Melvin Hochster, Expanded radical ideals and semiregular ideals . . . . . . . . . 553

Keizō Kikuchi, Starlike and convex mappings in several complex variables . . . . . . 569

Charles Philip Lanski, On the relationship of a ring and the subring generated by its

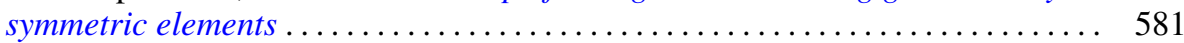

Jimmie Don Lawson, Intrinsic topologies in topological lattices and semilattices ........................................... 593

Roy Bruce Levow, Counterexamples to conjectures of Ryser and de Oliveira ...... 603

Arthur Larry Lieberman, Some representations of the automorphism group of an infinite continuous homogeneous measure algebra ..........

William George McArthur, $G_{\delta}$-diagonals and metrization theorems $\ldots .$.

James Murdoch McPherson, Wild arcs in three-space. II. An invariant of

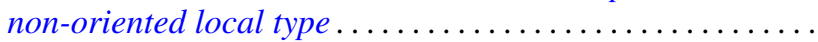

H. Millington and Maurice Sion, Inverse systems of group-valued measures ...

C. Edward Moore, Concrete semispaces and lexicographic separation of convex

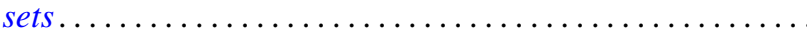

Jingyal Pak, Actions of torus $T^{n}$ on $(n+1)$-manifolds $M^{n+1}$.

Merrell Lee Patrick, Extensions of inequalities of the Laguerre and Turán type . . . . 675

Harold L. Peterson, Jr., Discontinuous characters and subgroups of finite index. . . . 683

S. P. Philipp, Abel summability of conjugate integrals . . . . . . . . . . . . . 693

R. B. Quintana and Charles R. B. Wright, On groups of exponent four satisfying an

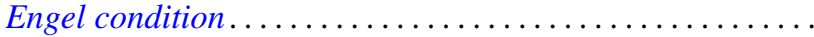

Marlon C. Rayburn, On Hausdorff compactifications. . . . . . . . . .

Martin G. Ribe, Necessary convexity conditions for the Hahn-Banach theorem in

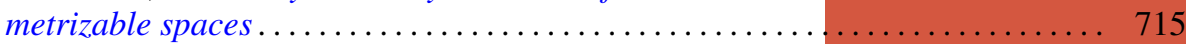

Ryōtarō Satō, On decomposition of transformations in infinite measure spaces .... 733

Peter Drummond Taylor, Subgradients of a convex function obtained from a

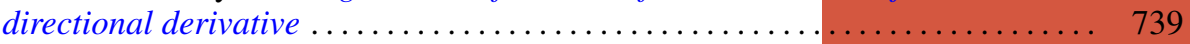

James William Thomas, A bifurcation theorem for $k$-set contractions . . . . . . . . 749 Clifford Edward Weil, A topological lemma and applications to real functions . . . . 757

Stephen Andrew Williams, A nonlinear elliptic boundary value problem . . ....... 767

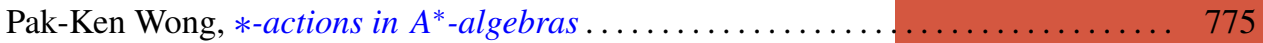

